\title{
SWI/SNF-Related Matrix-Associated Actin- Dependent Regulator of Chromatin Subfamily E Member 1
}

National Cancer Institute

\section{Source}

National Cancer Institute. SWI/SNF-Related Matrix-Associated Actin-Dependent

Regulator of Chromatin Subfamily E Member 1. NCI Thesaurus. Code C19840.

SWI/SNF-related matrix-associated actin-dependent regulator of chromatin subfamily $E$ member 1 (411 aa, $47 \mathrm{kDa}$ ) is encoded by the human SMARCE1 gene. This protein is involved in both transcriptional regulation and nucleosome topology. 